\title{
Exploring the sorption mechanism of tungsten on birnessite with stable isotopes
}

\author{
ChANDA P. ${ }^{1 *}$, FARMER J. C. ${ }^{2}$, WASYlEnKI L. E. ${ }^{1,2}$
}

${ }^{1}$ School of Earth and Sustainability, Northern Arizona University, Flagstaff, AZ 86011, U.S.A (*correspondence: Piyali.Chanda@nau.edu)

${ }^{2}$ Dept. of Chemistry \& Biochemistry, Northern Arizona University, Flagstaff, AZ 86011, U.S.A.

Tungsten (W) is considered to be an environmental contaminant because toxic effects on biota, including human health issues (e.g., cancer), are associated with elevated exposure to $\mathrm{W}$ in nature [1]. Sorption of $\mathrm{WO}_{4}{ }^{2-}$ onto nanoparticulate $\mathrm{Fe}$ - and Mn-oxides, which are ubiquitous, strongly controls $\mathrm{W}$ mobility in oxidized soils and aquifers. However, the mechanism of $\mathrm{WO}_{4}{ }^{2-}$ sorption and how it relates to solution chemistry, aqueous speciation, substrate composition, and surface complexations are still unclear. Stable metal isotopes often reflect subtle differences in bonding environments between aqueous and sorbed species, even at low metal concentrations that are inaccessible to frequently used spectroscopic methods such as EXAFS. Hence, we examined stable $\mathrm{W}$ isotope fractionation to explore the sorption mechanism of $\mathrm{WO}_{4}{ }^{2-}$ onto birnessite.

Time-series experiments with $\sim 0.6 \mathrm{mg}$ of synthetic birnessite and $\sim 600 \mathrm{ppb} \mathrm{W}$ in water, at $\mathrm{pH} 5$, reveal a continuously increasing extent of $\mathrm{W}$ sorption over three weeks. We observe a gradual shift in the magnitude of isotopic fractionation between dissolved and sorbed $\mathrm{W}$ as sorption extent increases. In short-term reactors (3-24 hr.), with $<50 \%$ sorbed $\mathrm{W}, \Delta^{183 / 182} \mathrm{~W}$ was +0.23 to $+0.44 \%$. However, long-term reactors ( $>24 \mathrm{hr}$.), with $>60 \% \mathrm{~W}$ sorption, show larger fractionations $(+0.53$ to $+0.89 \%)$ ). Our results differ somewhat from the results of [2], likely due to different $\mathrm{pH}$ (5 versus 8 ) and ionic strength ( 0 versus $\sim 0.7 \mathrm{M}$ ). Neither equilibrium nor Rayleigh fractionation trends fit our data set perfectly, implying the possibility of combined kinetic and equilibrium effects. We hypothesize that our results reflect initial rapid sorption of a monolayer of $\mathrm{W}$, followed by slow growth of a polymeric $\mathrm{W}$ surface precipitate in the later time points, as documented previously for $\mathrm{W}$ on boehmite [3]. Our experiments highlight the utility of stable isotopes to probe the sorption mechanism of $\mathrm{W}$ on birnessite.

[1] Dutta et al., (2017) Curr. Pollut. Rep. 3, 55-64. [2] Kashiwabara et al., (2017) GCA 204, 52-67. [3] Hur and Reeder (2016) J. Colloid Interf. Sci. 461, 249-260. 